\title{
Evaluation of Clinicoradiological Orofacial Structures in Children with $\beta$-thalassemia Major
}

\author{
Megha Pradhan ${ }^{1}$, P Sudha ${ }^{2}$
}

\begin{abstract}
Background: Thalassemia is one of the most common genetic disorders worldwide. Orofacial manifestations are the result of bony changes occurring due to ineffective erythropoiesis, with the formation of a bone-expanding erythroid mass. The orofacial manifestations such as saddle nose, prominent malar bones, and proclined anteriors lead to characteristic "rodent facies." Growth impairment is observed in most of the patients even under regular transfusions along with delayed dental development.

Aims and objectives: To assess the orofacial manifestations clinically, compare the difference between chronological and dental age of $\beta$-thalassemia major subjects with that of normal using the Demirjian's method radiographically, and also to find out any association between the pretransfusion hemoglobin and dental development.

Materials and methods: Forty $\beta$-thalassemia major-diagnosed subjects aged 3-16 years on regular blood transfusion were examined clinically for assessment of their orofacial features. Demographic data were collected including the pretransfusion hemoglobin level for at least 6 months. The "DMFT" and "dmft" indices were also assessed. Dental development was assessed along with their age- and sex-matched normal controls using the Demirjian's method for age estimation. Results were compiled and subjected to the statistical analysis.

Results: Majority of the thalassemic patients in the study were in their first decade. Saddle nose was the commonest orofacial manifestations observed while the characteristic feature "rodent facies" was seen only in $9(22.5 \%)$ subjects. The "DMFT" and "dmft" indices were high in thalassemic subjects than normal. Out of the $40 \beta$-thalassemia major subjects, 37 demonstrated delay in development of their dentition by 7 months than the controls, which was significant statistically. No association could be found between pretransfusion hemoglobin and the delay observed.

Conclusion: Decline in the occurrence of the "rodent facies" indicative of severe facial bone deformation could indicate the benefits of early diagnosis and regular transfusion but growth impairment in the form of dental developmental delay seen postulates a multifactorial etiology. Awareness must be given to $\beta$-thalassemia major subjects and their parents about oral health to achieve a better quality of life.

Keywords: Chronological age, Demirjian's method, Dental age, $\beta$-Thalassemia major.

Journal of South Asian Association of Pediatric Dentistry (2020): 10.5005/jp-journals-10077-3042
\end{abstract}

\section{INTRODUCTION}

$\beta$-thalassemia major or Cooley's anemia is the most severe form of thalassemia in which complete lack of $\beta$-protein in the hemoglobin ${ }^{1}$ is seen, which results in ineffective erythropoiesis, hemolytic anemia, and hypochromia with microcytosis. ${ }^{2}$ Systemic manifestations of untreated $\beta$-thalassemia major are hypersplenism, hepatomegaly, cardiomyopathy, cirrhosis, and endocrine dysfunction. Skeletal changes resulting from this disease are striking. Growth of marrow cavities causes skeletal deformities, thinning of cortical potions of bones (osteoporosis), and pathologic fractures. Growth and development in children is slow. Bimaxillary protrusion and other occlusal abnormalities are frequent in thalassemia major cases. Dental and facial abnormalities include spacing of teeth, open bite, prominent malar bones, protrusive maxilla, saddle nose, "rodent face," and pale oral mucosa. ${ }^{3}$ The class II skeletal pattern is frequently seen in such patients. ${ }^{4}$ Pain and swellings in the parotid glands in patients with thalassemia major have been reported, possibly as a result of iron deposits in the serous gland. ${ }^{5}$ Dental caries was also seen to be significantly increased in $\beta$-thalassemia major. ${ }^{6}$ Dental maturity, often expressed as dental age, is an indicator of the biologic maturity of a growing child. ${ }^{7}$ The development of dentition in thalassemia is seen to be significantly delayed by approximately 1 year. The amount of delay progressively increases as the thalassemic patients become older. ${ }^{8}$ Mean delay of $28 \%$ in skeletal maturation was seen compared to $17 \%$ delay in dental formation. ${ }^{9}$ Delay in the onset of transfusions
${ }^{1}$ Department of Pedodontics and Preventive Dentistry, Kathmandu Medical College and Teaching Hospital, Bhaktapur, Nepal

${ }^{2}$ Department of Pedodontics and Preventive Dentistry, Manipal College of Dental Sciences, Mangaluru, Karnataka, India

Corresponding Author: Megha Pradhan, Department of Pedodontics and Preventive Dentistry, Kathmandu Medical College and Teaching Hospital, Bhaktapur, Nepal, Phone: +977 9851133477, e-mail: drmeghapradhan@gmail.com

How to cite this article: Pradhan $M$, Sudha P. Evaluation of Clinicoradiological Orofacial Structures in Children with $\beta$-thalassemia Major. J South Asian Assoc Pediatr Dent 2020;3(1):23-26.

Source of support: Nil

Conflict of interest: None

and splenectomy as well as failure to maintain satisfactory hemoglobin levels are important factors in development of cephalofacial deformities. ${ }^{10}$ If blood transfusions have been carried out since birth, up to $50 \%$ of patients may either not present the clinical manifestations or do so only in a mild form. ${ }^{11}$

This study aimed to assess the orofacial manifestations in $\beta$-thalassemia major children and radiographically compare the difference between their chronological and dental age with that of normal using the Demirjian's method. An attempt to find out the association between the pretransfusion hemoglobin and dental development was also being made in the study. 


\section{Materials and Methods}

A study was conducted in the Department of Pedodontics and Preventive Dentistry, after ethical clearance from the Time bound Research Ethics Committee of the same institution. Forty $\beta$-thalassemia major-diagnosed subjects aged 3-16 years on regular blood transfusion who required orthopantomogram for their dental consultation within a span of 1 year were included in this study. Forty age- and sex-matched children visiting Department of Pedodontics and Preventive Dentistry for their dental treatment who required orthopantomogram for their diagnosis and treatment plan were taken as controls. Participants were selected by the purposive sampling technique. Individuals with special needs, acute febrile illness, and multiple systemic complications were excluded from the study.

In order to assess the degree of dental development and chronologic age, the participants were divided into two groups: in group $\mid<8$ years and in group $I \mid>8$ years. Prior to the study, an informed written consent was obtained from parents or guardian of each participants. Detailed case history along with general and oral examination was taken. The pretransfusion hemoglobin levels were obtained from the thalassemic subjects' medical records and the mean value was calculated for at least 6 months. Date of birth was recorded in order to ascertain exact age of the children. The chronological age was obtained by subtracting the date of panoramic radiograph taken from the exact birth date of the subjects. The panoramic radiograph of each individual was used to assess subjects' dental age by employing the method given by Chaillet and Demirjian. ${ }^{12}$ Mandibular left seven teeth \{second molar $\left(M_{2}\right)$, first molar $\left(M_{1}\right)$, second premolar $\left(P M_{2}\right)$, first premolar $\left(P M_{1}\right)$, canine $(C)$, lateral incisor $\left(\mathrm{I}_{2}\right)$, central incisor $\left(\mathrm{I}_{1}\right)$ \} were rated on an eight-stage scale from $\mathrm{A}$ to $\mathrm{H}$ according to the Demirjian's method revisited. ${ }^{13}$ Each stage was converted to numbers from 2 to 9. Addition of stage 0 and stage 1 was done where stage 0 indicated the tooth not yet calcified while stage 1 indicated the visible bony crypt without dental germ inside. For each OPG, 10 stages from 0 to 9 were given for each tooth and each stage of the seven teeth had been given a sex-specific, biologically weighted score. The maturity score was converted in dental age using appropriate tables of percentile curves and the 50th percentile curve was taken for calculation in obtaining the dental age. The percentile graphs were enlarged up to five times its original size for ease of evaluation. To avoid bias, intraobserver variability was calculated using Kappa statistics. Data obtained were analyzed using the Statistical Package for Social Sciences (SPSS) version 11.5 for Windows. Mean difference of age estimated by the Demirjian's method and the chronological age was calculated using the paired " $t$ " test. Correlation between chronological and dental age in both the cases and controls was determined. The Mann-Whitney test was done to assess the caries index and also the interobserver variability. The level of significance was $p<0.05$. The Pearson's correlation coefficient test was performed to assess the relation between dental developmental delay seen and the pretransfusion hemoglobin.

\section{Results}

Among the 40 thalassemic subjects, $67.5 \%$ were in their first decade while rest were in their second decade indicating their limited life expectancy.

Equal distribution was seen between males 20 (50\%) and females 20(50\%) in $\beta$-thalassemia major subjects as well as controls.
Majority of $\beta$-thalassemia major subjects $(39,97.5 \%)$ had not done splenectomy. Pallor and icterus were seen in 37 (92.5\%) and 4 (10\%) subjects, respectively. Saddle nose, prominent malar bone, frontal bossing, and "rodent face" were seen in 30 (75\%), 14 (35\%), 9 (22.5\%), and 9 (22.5\%) subjects, respectively. Angle's class I occlusion for permanent dentition was seen in 30 (75\%) cases while Angle's class II malocclusion was found in only $3(2.9 \%)$ of subjects. Mesial step deciduous molar relation was seen among 28 (70\%) subjects.

Gingivitis was seen in 4 (10\%) indicating normal gingival health among majority of the thalassemic subjects. The mean "DMFT" and "dmft" score recorded for $\beta$-thalassemia major subjects was 2.15 and 4.54 while that for the controls was 1.50 and 3.80, respectively.

Out of $40 \beta$-thalassemia major subjects, 37 (92.5\%) demonstrated delay in development of their dentition. The mean delay between the chronological and dental age in subjects was $1.0280 \pm 0.71$ while that for controls was $0.44 \pm 0.59$ years. The difference between chronological age and dental age calculated in case and control was statistically significant $(p<0.001)$ (Table 1$)$.

Mean chronological age of the $\beta$-thalassemia major subjects was $8.45 \pm 3.5$ years and that of controls was $8.66 \pm 3.6$ years. Majority of cases and controls showed underestimation while calculating the difference between chronologic and dental age. There was no significant difference between the delay seen in males and females both in the cases and the controls. The range of delay was from 0.23 to 2.25 years.

The dental development was seen to be delayed more in $\beta$-thalassemia major subjects by 7 months than the controls, which is significant statistically $(p<0.001)$ (Table 2$)$. Dental developmental delay was seen to be higher in age group $>8$ years both in cases $(1.07 \pm 0.72$ years) and controls ( $0.528 \pm 0.61$ years) when compared with children $<8$ years where the mean delay in cases was 0.98 \pm 0.71 years and controls $0.35 \pm 0.56$ years and the results were statistically significant (Table 3 ).

The mean pretransfusion hemoglobin recorded for all the thalassemic patients was $(7.75 \pm 0.91)$. The age of onset of transfusion started from as early as 1 month to 66 months. The dental developmental delay showed negative correlation with the age at which the transfusion started in the $\beta$-thalassemia major children $(r=0.176)$. More the age was at which the transfusion commenced, less was the delay in development (Table 4). The frequency of transfusion done showed no statistically significant difference in dental developmental delay.

\section{Discussion}

$\beta$-thalassemia major challenges the clinicians and alerts to be aware of possible oral manifestations and complications that may arise as a result of disease process and its treatment.

Splenectomy is reserved for patients with excessive transfusion requirements due to hypersplenism and difficulty in iron overload and is generally recommended to perform after 5 years of age. ${ }^{2}$ In this study, 39 (97.5\%) had not done splenectomy, which might have been due to their regular blood transfusions.

The red blood cell survival in thalassemia major is variable and usually decreased ranging between 6.5 days and 19.5 days, compared with the normal half-life of 25-35 days. Pallor is correlated to their degree of anemia. ${ }^{14}$ As subjects were examined just before their transfusions, pallor was seen in $92.5 \%$ indicative of anemia in majority of the subjects. Hemolysis results in excessive bilirubin production leading to clinical manifestations of icterus ${ }^{15}$ were seen only in $10 \%$ of the subjects. 
Table 1: Dental development by the Demirjian's method

\begin{tabular}{llllll}
\hline Thalassemia/normal & & Mean & Std. deviation & $t$ & $p$ \\
\hline Case (thalassemia) & $\begin{array}{l}\text { Chronological age- } \\
\text { calculated age }\end{array}$ & 1.0280 & 0.71282 & 9.121 & $<0.001$ \\
Control (normal) & $\begin{array}{l}\text { Chronological age- } \\
\text { calculated age }\end{array}$ & 0.4450 & 0.59193 & 4.755 & $<0.001$ \\
\hline
\end{tabular}

Table 2: Comparison between mean dental delay seen in cases and controls

\begin{tabular}{llllll}
\hline Thalassemia/control & $n$ & Mean & Std. deviation & $t$ & $p$ \\
\hline Case (thalassemia) & 40 & 1.0280 & 0.71282 & 3.98 & $<0.001$ \\
Control (normal) & 40 & 0.4450 & 0.59193 & & \\
\hline
\end{tabular}

Table 3: Dental delay seen according to age groups

\begin{tabular}{lllllr}
\hline Thalassemia/control & Chronological age & Mean & Std. deviation & $t$ & $p$ \\
\hline Case (thalassemia) & $<8$ & 0.9820 & 0.71592 & 6.134 & $<0.001$ \\
& $>8$ & 1.0740 & 0.72523 & 6.623 & $<0.001$ \\
Control/normal & $<8$ & 0.3511 & 0.5655 & 2.634 & 0.017 \\
& $>8$ & 0.5218 & 0.6149 & 3.980 & 0.001 \\
\hline
\end{tabular}

Table 4: Correlation between onset of transfusion therapy and dental developmental delay

\begin{tabular}{|c|c|c|c|}
\hline $\begin{array}{l}\text { Thalassemial } \\
\text { control }\end{array}$ & & & $\begin{array}{l}\text { Age at transfusion } \\
\text { started in months }\end{array}$ \\
\hline \multirow[t]{3}{*}{$\begin{array}{l}\text { Case } \\
\text { (thalassemia) }\end{array}$} & Delay & $\begin{array}{l}\text { Pearson } \\
\text { correlation }\end{array}$ & -0.176 \\
\hline & & Sig. (two-tailed) & 0.276 \\
\hline & & $n$ & 40 \\
\hline
\end{tabular}

The main cause for oral manifestations of thalassemia is extreme compensatory hyperplasia of the bone marrow; this in turn leads to expansion of the marrow cavity. ${ }^{16}$ In the study, saddle nose was found to be present in majority of the thalassemic subjects $(30,75 \%)$, which was also observed by Salehi et al. ${ }^{17}$ and Ficarra. ${ }^{18}$ Malar prominence, saddle nose, and frontal bossing contribute to formation of the characteristic "rodent facies."16 Only nine (22.5\%) subjects had frontal bossing, which could have resulted in less number of subjects with "rodent faces," in contrast to findings by Salehi et al. ${ }^{17}$

Early fusion of occipital sutures and hyperplasia of anterior maxillofacial structures result in maxillary protrusion ${ }^{19,20}$ and might be the reason for the proclined maxillary incisors seen in majority (47.5\%) of the subjects.

The development of the class II pattern has been attributed to the fact that mandible grows slower and also is blocked by the excessive vertical maxillary growth. ${ }^{21}$ In the present study, class II malocclusion was found in only $2.9 \%$ of cases in contrast to the studies done by Salehi et al. ${ }^{17}$ and Pusaksrikit et al. ${ }^{21}$

Caries is a disease of multifactorial etiology and various etiological factors indicated in thalassemia major as stated by literature are varying degrees of malocclusion, ${ }^{6}$ lower IgA level in saliva, ${ }^{22}$ endocrine dysfunction, and higher colonization with Streptococcus mutans. ${ }^{23}$ Prevalence of dental caries was higher in thalassemic subjects than in normal, suggesting a need for restorative dental care in thalassemics. These findings are in accordance with the study done by Anand et al., ${ }^{24}$ Al Wahadni, ${ }^{6}$ Mehdizah et al., ${ }^{25}$ Luglie et al., ${ }^{26}$ and De Mattia et al. ${ }^{11}$ Lack of dental awareness, education, and care, as well as poor oral hygiene and improper dietary habits and difficulties accessing preventive and restorative procedures, ${ }^{27}$ can play a significant role in the prevalence of caries among thalassemic patients. The other possible reasons could be parents of the patients are more concerned with the serious physical problems, paying less attention to the dental ailments as suggested by Kalpan et al. ${ }^{28}$

Thirty-seven thalassemic subjects demonstrated delay in development of their dentition, which was also seen by Hazza'a et al. ${ }^{8}$ Underestimation was seen both in cases and controls in contrast to studies. ${ }^{29-31}$ There was significant delay in development of thalassemic dentition with average of 7 months. An increase in delay of development resulted as the thalassemic patient grew older similar to Hazza'a et al., ${ }^{8}$ although some of their findings such as lack of significant difference in dental developmental delay below 8 years is in contrast to the present study as both age groups had significant difference.

In this study, the mean pretransfusion hemoglobin recorded for the thalassemic subjects was $(7.75 \pm 0.91) \mathrm{g} / \mathrm{dL}$, which was less than the standard optimal pretransfusion hemoglobin. The dental developmental delay showed negative correlation with the age at which the transfusion started in the thalassemic subjects $(r=$ 0.176). No statistically significant correlation could be established between the level of pretransfusion hemoglobin calculated for at least 6 months and the dental developmental delay. This is contrary to the findings of some other studies that showed correlation between growth retardation and low pretransfusion hemoglobin levels, implicating chronic hypoxia as a cause of growth retardation. ${ }^{32,33}$ Thus, growth retardation could have a multifactorial etiology. Among the contributory factors shown in various literature are suboptimal blood transfusions, hematological 
variants, iron overload, desferrioxamine toxicity, delayed puberty or abnormalities of the thyroid and growth hormone (GH) - insulinlike growth factors axis, ${ }^{34,35}$ deficiencies of micronutrients, including zinc, folic acid, and vitamin $\mathrm{B}_{12}{ }^{36}$ and undernutrition. ${ }^{37}$ So, other contributory factors are needed to be considered for growth impairment in $\beta$-thalassemia major subjects.

\section{ConcLusion}

Decline in the occurrence of "rodent facies" indicative of severe facial bone deformation could indicate the benefits of early diagnosis and regular transfusion in $\beta$-thalassemia major subjects but growth impairment in form of dental developmental delay seen in them postulates a multifactorial etiology and emphasizes the need for regular optimum transfusions and constant monitoring. Apart from their systemic problems, awareness must be given to those patients and their parents about oral health to achieve a better quality of life.

\section{Acknowledgment}

I would like to thank Dr Ashith B Acharya, Professor and Head, Department of Forensic Odontology, SDM College of Dental Sciences and Hospital, for his guidance in completion of this study.

\section{References}

1. Ay ZY, Oruçoğlu A, KInç $G$, et al. Does periodontal health of thalassemia major patients have an impact on the blood lipid profiles. J Pediatr Hematol Oncol 2007;29(10):694-699. DOI: 10.1097/ MPH.0b013e31814d68c3.

2. Hoffman R, Benz EJ, Shallil SJ, et al. Hematology basic principles and practices. . 4th ed. pp. 558-559.

3. Van Dis ML, Langlais RP. Thalassemias: oral manifestations and complications. Oral Surg Oral Med Oral Pathol 1986;64(2):229-233. DOI: 10.1016/0030-4220(86)90055-1.

4. Elham SJ, Abu Alhaija ESJ, Hattab FN, et al. Cephalometric measurements and facial deformities in subjects with $\beta$-thalassemia major. Eur J of Orthod 2002;24(1):9-19. DOI: 10.1093/ejo/24.1.9.

5. Goldfarb A, Nitzan DW, Marmary Y. Changes in the parotid salivary glands of $\beta$-thalassemia patient due to hemosiderin deposits. Int J Oral Surg 1983;1-12(2):115-119. DOI: 10.1016/s0300-9785(83)80007-6.

6. Al-Wahadni AM, Taani DQ, Al-Omari MO. Dental diseases in subjects with $\beta$-thalassemia major. Community Dent Oral Epidemiol 2002;30(6):418-422. DOI: 10.1034/j.1600-0528.2002.00012.x.

7. Nykanen R, Espeland L, Kvaal SI, et al. Validity of the demirjian method for dental age estimation when applied to Norwegian children. Acta odontol scand 1998;56(4):238-244. DOI: 10.1080/00016359850142862.

8. Hazza'a AM, Al-Jamal G. Dental development in subjects with thalassemia major. J Contemp Dent Pract 2006;7(4):63-70. DOI: 10.5005/jcdp-7-4-63.

9. Laor E, Garfunkel A, Koyoumidijsky-Kaye E. Skeletal and dental retardation in $\beta$-thalassemia major. Hum Biol 1982;54(1):85-92.

10. Logothetis J, Constantoulakis M, Lowenson RB. Cephalofacial deformities in thalassemia major (Cooley's anemia). Amer J Dis Child 1971;121(4):300-306. DOI: 10.1001/archpedi.1971.02100150074007.

11. Mattia De, Pettini PL, Sabato V, et al. Oromaxillofacial changes in thalassemia major. Minerva Pediatr 1996;48(1-2):11-20.

12. Chaillet N, Demirjian A. Dental maturity in South France: a comparison between Demirjian's method and polynomial functions. J Forensic Sci 2004;49(5):1059-1066. DOI: 10.1520/JFS2004037.

13. Demirjian A, Goldstein H. New systems for dental maturity based on seven and four teeth. Ann Hum Biol 1976;3(5):411-421. DOI: 10.1080/03014467600001671.

14. Cutando A, Gil JA, López JD. Thalassemia and their dental implications. Medicina Oral 2002;7:36-45.
15. Eleftheriou A. About thalassemia. Thalassemia International Federation Publications; 2007;4.

16. Helmi N, Bashir M, Shireen A, et al. Thalassemia review: features, dental considerations and management. Electron Physician 2017;9(3):4003-4008. DOI: 10.19082/4003.

17. Salehi MR, Farhud DD, Tohidast TZ, et al. Prevalence of orofacial complications in Iranian patients with $\beta$ - thalassemia major. Iranian J Publ Health 2007;36(2):43-46.

18. Ficarra G. Thalassemia diagnosed through facial distortion. Int J Maxillofacial surg 1987;16(2):23-25. DOI: 10.1016/S09015027(87)80136-4.

19. Cutando Soriano A, Gil Montoya JA, López-González Garrido Jde D. Thalassemias and their dental implications. Med Oral 2002;7(1): 36-40, 41-45.

20. Madhok S, Madhok S. Dental considerations in thalassemic patients. J Dent Med Sci 2014;13(6):57-62. DOI: 10.9790/0853-13645762.

21. Pusaksrikit $S$, Isarangkura $P$, Hathirat $P$. Cephalometric radiography in thalassemia patients. Birth Defects 1988;23(5A):421.

22. Siamopoulou-Mavridou H, Lapatsanis P. Flow rate and chemistry of parotid saliva related to dental caries and gingivitis in patients with thalassemia major. Int J Paediatr 1992;2(2):93-97. DOI: 10.1111/j.1365263x.1992.tb00016.x.

23. Ventura B. Cooley's anemia. its dental aspects. Clin Odont 1955;10:342-350.

24. Anand M, Garg S, Saraf BG, et al. A hospital based study of caries experience in beta -thalassemic major children. Acta Scientific Dental Sciences 2019;3(5):45-48.

25. Mehdizah M, Mehdizah M, Zamani G. Orodental complications in patients with major $\beta$-thalassemia. Dent Res J 2008;5(1):17-20.

26. Luglie PF, Campus G, Deiola C, et al. Oral condition, chemistry of saliva, and salivary levels of streptococcus mutans in thalassemic patients. Clin Oral Invest 2002;6(4):223-226. DOI: 10.1007/s00784-002-0179-y.

27. Hattab FN, Hazza'a AM, YassinOM, et al. Caries risk in patients with thalassemia major. Int Dent J 2001;51(1):35-38. DOI: 10.1002/j.1875595x.2001.tb00815.x.

28. Kalpan RI, Werther R, Castano FA. Dental and oral findings in Cooley's anemia: A study of fifty cases. Ann NY Acad Sci 1964;119:664-666.

29. Prasad H, Kala N. Accuracy of two dental age estimation methods in the Indian population - a meta-analysis of published studies. J Forensic Odontostomatol 2019;3(37):2-11.

30. Hegde RJ, Sood PB. Dental maturity as an indicator of chronological age. Radiographic evaluation of dental age in 6 to 13 years children of Belgaum using Demirjian methods. J Indian Soc Pedo Prev Dent 2002;20(4):132-138.

31. Prabhakar AR, Panda AK, Raju OS. Applicability of Demirjian's methods of age assessment in children of Davangere. J Indian Soc Pedo Prev Dent 2002;20(2):54-62.

32. Rodda CP, Reid ED, Johnson $S$, et al. Short stature in homozygous beta-thalassemia is due to disproportionate truncal shortening. Clin Endocrinol (Oxf) 1995;42(6):587-592. DOI: 10.1111/j.1365-2265.1995. tb02684.x.

33. Ortolani M, Wolman IJ. Some clinical features of Cooley's anemia patients as related to transfusion schedules. Ann NY Acad Sci 1969;163(1 Second Confer):407-414. DOI: 10.1111/j.1749-6632.1969. tb27811.x.

34. Kattamis CA, Liakopoulu T, Kattamis A. Growth and development with thalassemia major. Acta Paediatr Scand 1990;366(suppl):111-117. DOI: 10.1111/j.1651-2227.1990.tb11611.x.

35. Low LCK. Growth, puberty and endocrine function in betathalassemia major. J Pediatr Endocrinol Metab 1997;10(2):175-184. DOI: 10.1515/jpem.1997.10.2.175.

36. Saraya AK, Kumar R, Kailash S, et al. Vitamin B 12 and folic acid deficiency in $\beta$-heterozygous thalassemia. Ind J Med Res 1984;79: 783-788.

37. Fuchs GJ, Tienboon $P$, Linpisarn $S$, et al. Nutritional factors and thalassemia major. Arch Dis Child 1996;74(3):224-227. DOI: 10.1136/ adc.74.3.224. 